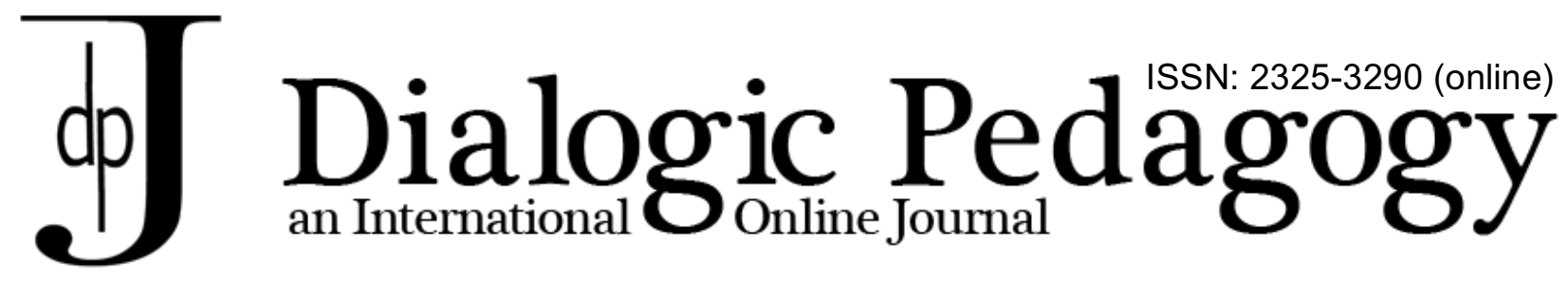

\title{
Aesthetics and the possibility of an anti-totalitarian communism: reading Bakhtin through the lens of Groys
}

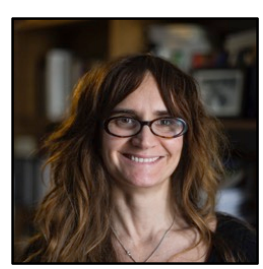

Antonia Larraín

Universidad Alberto Hurtado, Chile

Antonia Larraín is Associate Professor at Universidad Alberto Hurtado, Chile. She is PhD in Psychology at the Pontificia Universidad Católica de Chile, and was a visiting scholar at Faculty of Education, University of Cambridge, UK. Her current research is on the relation between classroom argumentation and learning, and the dialogical nature of psychological processes.

$\cos 0300$

Boris Groys, in his article Between Stalin and Dionysus: Bakhtin's Theory of the Carnival, advanced a particularly provocative reading of the political implications of Bakhtin's thought on the polyphonic novel and carnival. He claims that Bakhtin's theory is not to be read as a criticism of Stalinist totalitarianism from a democratic and liberal point of view:

\footnotetext{
Bakhtin's attitude to liberalism and democracy in their traditional meaning is that of deep antipathy: for him, they are synonymous to alienation, autonomization, clamming up of individuality, the separation of the latter from the natural unity of cosmic and people's life - and, consequently, they become the historical reasons for the emergence of the pathos of seriousness, sentimentality, moralizing, and, also, of the devolution of the people's carnivalesque laughter into individualistic criticism and satire (p. DB:3).
}

Bakhtin's theorisation around the carnival and polyphonic novel, according to Groys, should be read as an aesthetic response to the tragedy of the Revolution. The response is not a claim for democracy and/or individual rights, but an aesthetic transformation of horror into laughter (a religious act, according to William James, 1902/2009), based on the acceptance that community and/or people are verified as the unity of the social; as the principle (in the sense of the Greek arché) of social life.

The question about Bakhtin's original political intentions, or communicative will, is contradictory to his own main ideas - there is no such thing as an author coinciding with a man; or a speaking subject's will beyond the materiality of the text (Bakhtin, 1990). Thus, I will argue not from the perspective of what I believe Bakhtin (the man) was really trying to say, but from what I think Bakhtin (the author) already said. The main point that I seek to make is that, although I find Groys' non-democratic and liberal reading of Bakhtin's critique of totalitarianism extremely convincing and thoughtful, I am not persuaded by interpreting his political choice as an aesthetic reaction to the Revolution; as a religious and consoling verification of the tragedy. Groys suggests that we have two options when reading Bakhtin's theory of the 
carnival and polyphonic novel: either as a defense of democracy and liberal values; or an affirmation of the community as the social arché through the aesthetic reaction to one of its possibilities totalitarianism. From my reading of Bakhtin's works, I observed a third form of critique: the affirmation of the community as the social arché through the theorisation of totalitarianism impossibility.

From a reading of Bakhtin, totalitarianism turns out to be an impossible and futile enterprise, for the same reasons that liberalism is (according to Groys): totalities and/or individualities are not fixed entities defined by biological bodies or national boundaries. Totalities and individualities are only possible as intentional fabrications or products of aesthetic/artistic activity. On the contrary, life - real, social and discursive life - is an open, inconclusive and unpredictable process. It is open and inconclusive because there is no such thing as the first or final word: each utterance responds to many others, past or anticipated. Finalisation only comes when a word is responded to by a new word (Bakhtin, 1986), but then, beyond a definitive ending, a new beginning starts. Life is unpredictable because every response is an unrepeatable event and thus generative in its essence. The utterance is not a linguistic unit but a social one: the "utterance is a link in the chain of speech communion" (p. 93). Each utterance involves a social encounter; a relationship between two or more words, points of view and perspectives that occurs simultaneously at different levels and at different rates.

Therefore, the community may be the minimal unit of social life, but the real arché is the encounter, the responding act - the unpredictable act that creates a new response, opening a new discursive thread. This is the key to understanding the impossibility of totalitarianism. Social community, as a unit of social life, is constituted and driven by the dynamic of the encounter of two or more speakers, perspectives or ideological positions. The other is the real inconclusive boundary that ensures creativity and continuous life; and that other changes constantly, as do the boundaries. The community is not a concluded unit but an open, inconclusive and unpredictable configuration of multi-level responding acts. Community, then, is a dynamic whole (a complex system?) with no clear limits and boundaries; an everchanging whole in which novelty is always emerging from the past. What ensues is that innovations and new perspectives are constantly emerging and there is almost no possibility of having total centralised control: centripetal forces are contra-rested by centrifugal forces, which resist the complete unification of language and thinking (Bakhtin, 1981). Real and definitive closure and conclusion, both pre-requisites for liberalism and totalitarianism, are not possible in real life, according to Bakhtin's account; social life is an open process that, at the same time, is continuously tending towards a closure that never comes, and originating novelty from what is already known and old.

Openness and inconclusiveness, as main features of community dynamics, are not synonymous with the fractional. Bakhtin insisted, throughout many texts, upon the notion of utterance and genres (1986), even languages (1981), as wholes. Utterances are wholes in the moment they can be (or are) responded to. It is the actual or anticipated response (the reaction of the alter) that renders a unit of living discourse a whole. Therefore, the whole is the encounter, the rejoinder. The whole is the social bond: it is not one or the other perspective that is linked, but the point of union of different views (See Haye \& Larraín, 2011). Thus, the whole is always, and by definition, plural, incontrollable and heterogeneous. Community as a whole is a complex living system, not an identical entity, and it is precisely this idea that renders totalitarianism an impossible achievement, a ridiculous spectacle. Bakhtin may be aesthetically transforming his (their) suffering into laughter, but he is also arguing using logic against totalitarianism from a non-liberal perspective: from an anti-totalitarian communism.

How may this anti-totalitarian communism lead to social organisation? One possibility is to read Bakhtin from the theories of complex systems and to think that order, organisation and control are 
achieved in a distributed and local way (Ladymar, Lambert, \& Wiesner, 2013). However, to a certain degree we need closure to organise our lives; to make decisions; and to understand; and we (as selves, as communities, as nations) fabricate these closures. Art and aesthetics are among the ways in which we fabricate closed entities, external objects, and experience them from the outside, taking a perspective that is necessary in order to regulate ourselves, to elaborate experiences and to continue living. For instance, regarding the self, we cannot live in the complete openness and dynamic heterogeneity of ourselves. Thus, we are constantly producing aesthetic closures (i.e. biographical stories) in which we take a position outside ourselves (extra-positions) to fabricate closed versions of ourselves that allow us to emotionally elaborate our experience and understand it - versions in which we are, at the same time, author and heroes (see Bakhtin, 1990). Aesthetics, then, plays a critical role in the development and formation of the sense of self: through the constant aesthetic/artistic fabrication of ourselves (our families, our communities, our countries) and through/in language, we achieve a sense of me/we. Bakhtin (1990) describes this aesthetic process as consisting of three steps: 1) the active imagination of the other and how the other sees us; that is, to see ourselves through the eyes of the other; 2) the emphatic vivification of the emotional and volitional world of the other that sees us; that is, ethical empathy; and 3) the clear consciousness that that other, that is, how I'm seeing my self as other, is not the whole story; the clear consciousness of the impossibility of full closure.

This aesthetic activity, in a way, is an inherent part of discursive activity: every utterance necessarily involves composition and formal verbal (artistic) creation. However, this creative activity may be more or less systematic insofar as there are speech genres that may facilitate this kind of activity better than others (i.e. autobiographical novels or memoires, collective creations, among others). Through this aesthetic process people appropriate a systematic way of dealing with otherness and selfness in a productive way, promoting both social and self understanding. It represents, in a way, a different form of deliberation and consideration of different perspectives that is based not on the rational consideration of others' perspectives, but on the aesthetical extraposition and the ethical consciousness of our own interdependence.

This idea has interesting implications for education and educational systems. Understandings cannot be achieved in response to a centralised and totalising demand for them. Conventional meanings are embedded in larger social and historical practices from which cannot be detached. However, these meanings are typically taught at school detached from their 'background of understandings' (Bakhtin, 1981). In order to be understood those conventional meanings need to be recreated making these backgrounds explicit and opening them to consideration. The recreation of conventional meanings, the reconstruction of these backgrounds of understanding, does not occur through a clean logical activity: it involves artistic creation and fiction. For really understanding conventional meanings, meanings that arose elsewhere for purposes that are not evident for me, I need to imagine, to produce a partly fictional idea of their relations to other meanings and historical roots.

Therefore, understandings are somewhat active processes of artistic fabrication of provisional and partial closures that need to be locally pursued. School learning and the understanding of social and historically created ideas and tools depend on the fabrication of local aesthetic closures at multiple levels (classroom, grades, schools, communities). Local agency then is the heart of education. This is not news. However, here I am not thinking of agency in a liberal way, that is, an agency as a unknown force whose source is the already constructed unit (individuals, schools, communities). Here I am conceiving of agency precisely as the movement of fabricating that unity, of fabricating and becoming a totality regarding which it is possible to take a perspective for understanding, of appropriating knowledge in an aesthetic way, that is, through its artistic expropriation. 
In synthesis, through the artistic daily verbal creation, we unfold an aesthetic activity that is crucial to the sense of understanding us, understanding others and understanding socio-historically created ideas. The product is not a transcendental work of art, but a provisional and partial vision of our own personality, position or knowledge and their fragility: our inconclusiveness and radical dependence on others. If aesthetic activity is crucial to managing our daily social relations in their political, emotional and cognitive aspects, can we think that it is also a crucial aspect for the organisation of society? Can we think of aesthetics as a political method to cope with an open, unpredictable and inconclusive community? Is aesthetics, as a method of social deliberation for understanding, a key Bakhtinian contribution to an anti-totalitarian communism?

\section{References}

Bakhtin, M. (1981). Discourse in the novel. The dialogical imagination (pp. 4-256). (C. Emerson \& M. Holquist, Trans.). Texas: University of Texas Press.

Bakhtin, M. (1986). The problem of speech genres. Speech genres and other late essays (pp. 60-102). (V. W. McGee, Trans.). Texas: University of Texas Press.

Bakhtin, M. (1990). Author and hero in aesthetic activity. Art and answerability (pp. 4-256). (V. W. McGee, Trans.). Texas: University of Texas Press.

James, W. (2009). The varieties of religious experience: A study in human nature. Lexington, KY: Seven Treasures Publications. (Original work published 1902.)

Ladyman, J., Lambert, J., \& Wiesner, K. (2013). What is a complex system? European Journal for Philosophy of Science, 3(1), 33-67. 10.1007/s13194-012-0056-8

\section{(c)) EY}

New articles in this journal are licensed under a Creative Commons Attribution 4.0 United States License.

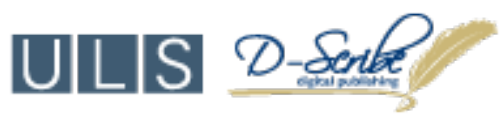

This journal is published by the University Library System, University of Pittsburgh as part of its D-Scribe Digital Publishing Program and is cosponsored by the University of Pittsburgh Press. 